\title{
Commentary
}

\section{Fight against Child Labor in Bangladesh: IUF v. Perfetti Van Melle}

\author{
By Yvonne Erkens, Associate Professor of Labor Law, Leiden University, \\ Leiden, the Netherlands
}

\section{Introduction}

On 9 August 2019, the International Union of Food, Agricultural, Hotel, Restaurant, Catering, Tobacco and Allied Workers' Associations (IUF), a global union federation based in Switzerland, submitted a specific instance to the Dutch National Contact Point (NCP) regarding an alleged violation of the OECD Guidelines for Multinational Enterprises (OECD Guidelines) by Perfetti Van Melle, which is headquartered in the Netherlands. The complaint concerned Perfetti Van Melle's operations in Gazipur, Bangladesh. According to the IUF, Perfetti Van Melle's wholly owned subsidiary in Bangladesh would not have respected the right to collective bargaining and freedom of association. Further, the IUF alleged that the company had employed child laborers, workers younger than eighteen, in its factory in Bangladesh. After several separate and confidential meetings with the companies and the IUF, the Dutch NCP prepared a draft initial assessment in which it concluded that the notification merited further consideration and offered its good offices to address the issues raised in the specific instance. The IUF accepted the good offices. Perfetti Van Melle denied the issues raised on the right to collective bargaining and freedom of association, but reserved its position on child labor until further evidence was provided. The NCP then organized a meeting between the parties to 
discuss child labor. On the basis of these outcomes, the NCP decided to close the specific instance with a final statement. ${ }^{1}$

\section{Analysis}

The IUF is an international federation of trade unions representing workers in: agriculture and plantations; the processing and manufacture of food and beverages; hotels, restaurants, tourism, and catering services; all stages of tobacco processing. Perfetti Van Melle is a multinational enterprise according to the Guidelines and claims to be the world's third largest manufacturer and distributor of confectionary and chewing gum. ${ }^{2}$ It comprises thirty-eight operating companies and thirty manufacturing facilities, sells its products in more than 15 o countries, and employs 17,80o people worldwide. An Italian family-owned business, it is headquartered in Amsterdam. ${ }^{3}$

The IUF alleged that Perfetti Van Melle through its wholly owned Bangladesh operating subsidiary has repeatedly violated basic rights set out in the Guidelines. The violations of the Guidelines are pervasive and of escalating severity in Perfetti Van Melle's Bangladesh operations and have continued despite communications from the IUf. The IUf accuses Perfetti Van Melle of counteracting the local union (PVM Union) by interfering in its registration process. In addition, IUf states that Perfetti Van Melle uses child labor. PVM Union mandated the IUF to directly address the use of child labor with Perfetti Van Melle corporate management because PVM Union claimed to be unable to address the issue itself on a local level. ${ }^{4}$

Perfetti Van Melle stated in a letter to the NCP that

'Perfetti Van Melle produces in Bangladesh for the local consumer market; we don't use Perfetti Van Melle Bangladesh as a 'low cost' production facility for other parts in the world. ... (...) Perfetti Van Melle fully supports the forming of the Union in Bangladesh. We have not organized any kind of physical, material or immaterial repression or coercion to the union representatives nor to any other worker of Perfetti Van Melle Bangladesh. We have invested in the development and training of the union

Dutch National Contact Point (NCP) for the OECD Guidelines for Multinational Enterprises, Final Statement, IUF vs. Perfetti Van Melle, 15 June 2020, 1.

$2 \quad$ Ibid., 2.2.

3 Ibid., 2.1, 2.2 .

4 Ibid., 3.1. 
members. (...) Perfetti Van Melle has never allowed and will never allow the use of Child Labour in our factories. We require a minimum age of our workers of 18 years and that (contractual) obligation also applies to our providers. With all what is possible, we have checks and balances in place to ensure the minimum age requirement of our workers. This approach continues; e.g. recently a sophisticated entrance system (finger print access) has been installed, the use of our labour supplier will be further reduced by bringing more people on our own payroll, and we continue to put pressure on authorities to give access to people data systems to validate workers' date of birth and identity. ${ }^{\prime 5}$

After having spoken with both the complainant and the company, the NCP prepared a draft initial assessment stating that this specific instance merited further consideration and offering to facilitate a dialogue on child labor and the rights to collective bargaining and freedom of association. On the latter rights, the company asserted that it had always fully supported them, and therefore refused to discuss the matter further with the complainant in the context of this NCP procedure. Regarding child labor, Perfetti Van Melle considered the initial assessment premature: the company first wanted to discuss the evidence for child labor in their Bangladeshi factory before making a decision on accepting the NCP's good offices. The IUF was open to deliver the evidence on child labour, but only in person, out of concerns for the safety of the concerned individuals. In light of these developments, the NCP proposed a meeting under its neutral chairmanship to focus on child labour. ${ }^{6}$ Both parties accepted and the meeting took place on 6 February 2020 .

Perfetti Van Melle stated that it firmly opposed any form of child labor. It clarified during the meeting that it was taking measures intended to ensure that no one under eighteen is employed in the Bangladeshi factory: phasing out of the involved third-party contractor by spring 2020, subjecting its employees to a thorough age verification process, raising the minimum age to twenty years, and installing a biometric identification verification system. Ultimately, because of the uncertainty about the ages of the employees, child labor in the company's factory in 2019 proved impossible to determine. The parties did agree that at that moment no children were employed in the Bangladeshi factory. ${ }^{7}$

$\begin{array}{ll}5 & \text { Ibid., 3.2. } \\ 6 & \text { Ibid., 4. } \\ 7 & \text { Ibid., 5.1. }\end{array}$


The NCP closed the specific instance with a final statement in which it recommended that the parties to this specific instance will remain in contact. It will ensure that the issues of child labor will not recur and will take responsibility for these processes at a higher level if needed. It observed to its satisfaction that Perfetti Van Melle has decided to phase out as a complicating factor the activities of Rahat Corporation. ${ }^{8}$ The NCP recommended an evaluation in the autumn of 2020 on the outcomes of the dialogue, specifically the agreements the parties reached and the follow-up of the NCP recommendations. ${ }^{9}$

\section{Conclusions}

In this specific instance procedure IUF raised the issue that in the Bengal subsidiary of Perfetti Van Melle union rights were being violated and child labor was being used. The company rejected discussion of violation of union rights, but was willing to take part in a discussion led by the Dutch NCP to enable IUF to provide evidence of child labor. During this meeting, IUF asserted having indications that among the employees working in the Bangladeshi factory of Perfetti Van Melle in 2019, twenty-five would have been younger than eighteen. For nine of these alleged underaged employees, according to the IUF, irregularities between the birth and primary school certificates indicated unreliable dates that had been tampered with. All of them would have been working in the factory through a third-party contractor. It was ultimately not possible for the parties to agree on the exact ages of these nine employees. It was therefore not possible to determine with certainty whether child labor had been in force in the factory in 2019. ${ }^{10}$ The parties reached an agreement during the meeting that there was at that moment no child labour in Perfetti Van Melle's factory in Bangladesh and measures were taken to prevent its occurrence in the future. The NCP then proposed not to publish an initial assessment, but to conclude this specific instance instead with a final statement. ${ }^{11}$

An initial assessment has two primary functions: first, it serves as a declaration of admissibility; second, it records the points of dispute between the parties. In this specific instance, the draft initial assessment could not be definitive because Perfetti Van Melle first wanted to discuss the evidence for child labor. The NCP succeeded in bringing the parties together for a related meeting.

\begin{tabular}{ll}
\hline 8 & Ibid., 6. \\
9 & Ibid., 6, 7. \\
10 & Ibid., 5.1. \\
11 & Ibid., 5.3.
\end{tabular}


When it became clear that the allegation of child labor could not be proven, the good offices of the NCP ended because Perfetti Van Melle had already indicated that it did not want to discuss the other allegation-breach of union rights - under NCP leadership. Contrary to the normal course of events, a final statement without a final initial assessment was published.

NCP s are not required to publish an initial assessment. ${ }^{12}$ Nonetheless, an initial assessment has an important function in determining the extent of the conflict after both parties have been consulted. This is part of the negotiation process, the ultimate goal of which is mediation by the NCP. The step taken by the Dutch NCP is therefore unusual, but given the circumstances was functional: because the NCP managed to get parties to talk about one of the two allegations, the parties reached an agreement that eliminated the need to finalize the concept initial assessment. Strictly speaking, the NCP could still have finalized the initial assessment on the other complaint, but that had been constrained once Perfetti Van Melle indicated that it would not accept any further NCP interference in this matter.

Apart from this procedural matter, this specific instance procedure also shows how companies struggle with preconditions that enable fundamental labor rights to be respected. If birth certificates are missing, it is difficult to verify a person's age. Perfetti Van Melle details the procedures the company uses to ensure that only those over the age of eighteen can enter the workplace. These procedures appear to be not foolproof: however benevolent, the company is confronted with conditions beyond its control.

Formally this specific instance seems to have ended on an uncertain note. Informally, however, certain achievements are clear: Perfetti Van Melle promised to raise the minimum working age to twenty and to limit hiring through an intermediary, which makes compliance easier. Moreover, in the aftermath the NCP stays involved by monitoring the agreements between the parties. 